THE INTERNATIONAL

REVIEW OF RESEARCH IN

OPEN AND DISTANCE LEARNING

\title{
Quality of Learners' Time and Learning Performance Beyond Quantitative Time-on-Task
}

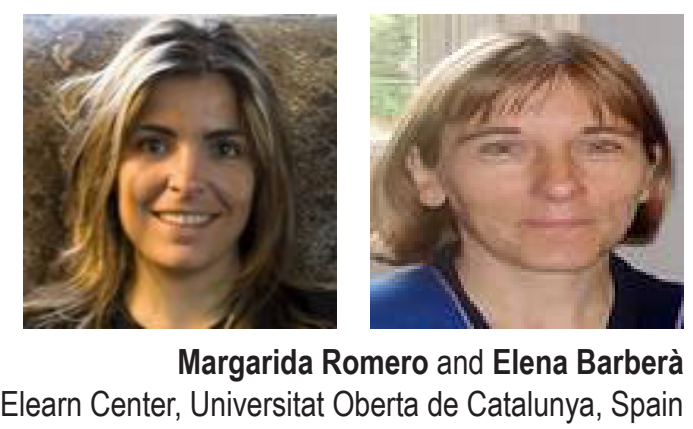

\section{Abstract}

Along with the amount of time spent learning (or time-on-task), the quality of learning time has a real influence on learning performance. Quality of time in online learning depends on students' time availability and their willingness to devote quality cognitive time to learning activities. However, the quantity and quality of the time spent by adult e-learners on learning activities can be reduced by professional, family, and social commitments. Considering that the main time pattern followed by most adult e-learners is a professional one, it may be beneficial for online education programs to offer a certain degree of flexibility in instructional time that might allow adult learners to adjust their learning times to their professional constraints. However, using the time left over once professional and family requirements have been fulfilled could lead to a reduction in quality time for learning. This paper starts by introducing the concept of quality of learning time from an online studentcentred perspective. The impact of students' time-related variables (working hours, timeon-task engagement, time flexibility, time of day, day of week) is then analyzed according to individual and collaborative grades achieved during an online master's degree program. The data show that both students' time flexibility $(r=.98)$ and especially their availability to learn in the morning are related to better grades in individual $(r=.93)$ and collaborative activities $(r=.46)$.

Keywords: E-learning; computer-supported collaborative learning; academic performance; e-learning quality; time flexibility; time-on-task; time quality; learner time 


\section{Introduction}

In assessing e-learning quality, the factor of time has been studied in relation to instructional time, examining a course's flexibility in terms of duration (Van den Brande, 1994), the pace of learning (Collis, Vingerhoets, \& Moonen, 1997), and the choice e-learners have about when to learn in an individualized way (De Boer \& Collis, 2005; Ehlers, 2004) without synchronicity constraints (Arneberg et al., 2007). Maintaining flexibility in the duration, pace, and time chosen for learning might ensure instructional quality but, far from guaranteeing learners' time-on-task quality, it invites time-poor e-learners to choose to spend insufficient time, to work too slowly, and to devote an inadequate number of time slots to learning in terms of the quality of cognitive time.

We believe the level of quality of cognitive time is defined by mental activity capabilities at a specific point in time, such as focus, information-processing capacity, consciousness, and higher-order cognitive skills (HOCS) like decision-making. The idea that learning takes time is shared both by researchers and educators, who state that students need "time to talk, write, reflect, and otherwise engage in activities" (Cross, 1999, p. 10) and must devote "time and effort to out-of-class studying" (Kolari et al., 2008), allowing them "to own their learning" (Wolk, 2001, p. 59). Quality e-learning requires quality in instructional time and quality in students' time. On the one hand, instructional time flexibility is one of the main reasons for enrolling in an online course (Schrum, 2002; Sullivan, 2001), and, on the other, time availability is one of the main constraints on distance learners when it comes to continuing with their studies (Vergidis \& Panagioutakopoulos, 2002).

Considering the relevance of instructional time and e-learners' time to successful online education, we have divided learning time into quantitative and qualitative categories. Motivation has been considered an important factor in students' decisions to devote quantitative time-on-task and in the desire to "persist and complete assigned tasks" (Dev, 1997). Besides the quantity of time learners spend on a task, the quality of this time affects their learning performance. Students' time quality in online learning depends on their availability, willingness, and motivation to devote quality cognitive time to online learning tasks. We begin by analyzing the implications of three major concepts in the online learners' time-on-task: time flexibility, time-on-task quantity, and time-on-task quality. We then move on to look at the impact of quantity of time-on-task and the attributes of time spent on the learning task and performance.

\section{Time Flexibility in E-Learning}

Time flexibility is one of the most appealing options offered by distance education (Felix, 2001; Valenta, Therriault, Dieter, \& Mrtek, 2001; Zhang, Zhao, Zhou, \& Nunamaker, 2004), allowing two kinds of time to be combined: instructional time and learners' time. From an instructional point of view, time flexibility means that academic learning time can be adapted to learners' availability and learning development. For students, we define time flexibility as the students' ability to regulate their time-on-task according to their learning time availability, the instructional time requirements, and the flexibility of the learning 
tasks. Learners' time flexibility is determined by their capacity to allocate time to academic activities and the quantity and quality of time they can spend on these activities. We should, therefore, consider online learning time flexibility in terms of both instructional time flexibility and student time flexibility.

Instructional time determines the duration, pace, and synchronicity of the learning activities that make up the learning program in which the student is involved. Collis identifies several different types of flexibility in online courses, including "time flexibility, content flexibility, entry and completion flexibility, instructional-approach flexibility, learningresource flexibility, technology-use flexibility, interactivity and communication flexibility, course-logistics flexibility, as well as location flexibility" (1998, p. 376). Instructional time flexibility, determined by the curriculum and flexibility of the learning activities, could be considered an externally regulated time flexibility. Schellekens, Paas, and Van Merriënboer (2003) also look at students' perception of this instructional flexibility subjectively, considering time flexibility as it is perceived by the learner. Both instructional time flexibility and students' perception of this flexibility have been considered indicators of e-learning quality (Arneberg et al., 2007; McGorry, 2003; Högskoleverket, 2008) and an expectation of e-learners (Ehlers, 2004; Harasim, 1990; Lorenzetti, 2005). However, time flexibility has also been regarded as a force working against course structure and quality (Kanuka, 2002), introducing the possibility that instructional flexibility and higher learner regulation could lead to lower learning quality.

Despite the fact that they have examined instructional and organizational flexibility, only a few studies take into account the time attributes of learners, such as time-on-task quality and time flexibility in terms of the time of day or day of the week. Online universities currently do not systematically consider the flexibility and quality of their students' time before accepting their enrolment. Regarding the system as one that can be used anywhere and anytime and misjudging both the amount and quality of time students have, online universities allow time-poor students to enrol in distance learning programs without considering whether they have sufficient time (in terms of quantity and quality) to succeed in a given program. Where traditional universities have the ability to ensure that their students devote a portion of their quality time by requiring them to attend classroom sessions, online educational institutions do not have a direct way to ensure the quantity and quality of their online learners' time-on-task because instructional time flexibility leads the learner to regulate it themselves (Romero \& Lambropoulos, 2011). By failing to measure learners' time-on-task qualitatively, educational institutions may be wasting their instructional time as a true knowledge asset (Boisot, 1998), which could be encouraging students to devote low-quality time to their learning activities. Grundspenkis and his colleagues believe that flexibility in instructional time could encourage the learner to study "at [an] inappropriate time, e.g., late evening, when he/she is very tired and therefore ineffective" (2006, p. 337). Considering that "the single most important variable [among students who succeeded with distance learning] is the students" (Moore \& Kearsley, 1996), we focus this study on time flexibility and quality from the online learners' perspective.

We looked at the significant differences in students' time flexibility in individual and collab- 
orative activities related to the use of synchronous communication in collaborative learning. In individual settings, students' time flexibility has been taken into account by Norwegian distance education authorities, who have been committed "to asynchronous communication and deliberately avoided synchronous communication technologies. Communication should take place when it suits the student, not the institution" (Arneberg et al., 2007, p. 7). Individual tasks allow students to organize their time-on-task allocation during an activity. In collaborative tasks with a certain degree of interdependence, students must coordinate their work. Despite the various asynchronous ways of carrying out the task, coordination involves a certain degree of time commitment at the group level that reduces individual time flexibility (Romero, 2010), leading students to believe that "online collaboration is not time-flexible at all” (Levinsen, 2006, p. 43).

\section{Quantity of Learning Time and Academic Performance}

Students' time availability is therefore a central element in e-learning activities because of the lack of time adults have, as the term "time scarcity" indicates (Douthitt, 2000). Students engaged in e-learning (and distance learning in general) are often adult learners who have work and family constraints (Diaz, 2002; Pallof \& Pratt, 2003). The time they can allocate to their learning activities is therefore reduced (after a day's work, while the children are asleep, on weekends, etc.), and is often the time left over once their professional, social, and family commitments have been fulfilled. Studies published on the time factor in academic performance have analyzed the relationship between time-on-task spent and academic performance, especially in the context of face-to-face education homework assignments. Wagner, Schober, and Spiel (2008) show a positive relationship between performance and the quantity of time allocated by postsecondary learners $(N=824)$. Using the German PISA data set in primary education ( $N=24,273)$, Trautwein (2007) observes that the frequency of homework is even more relevant in academic performance than the amount of time it takes to complete assignments. Other studies on time quantity and academic performance provide variable results, with a slight positive relationship between the quantity of study time and performance (Allen, Lerner, \& Hinrichsen, 1972, $r=.23$; Hinrichsen, 1972, $r=$ .32; Wagstaff \& Mahmoudi, 1976, $r=.31$ ) and indicate a negative relationship in some cases (Greenwald \& Gillmore, 1997, $r=-.15$ ). The analysis done by Schuman et al. concluded that "there is at best only a very small relationship between amount of studying and grades" (1985, p. 945). Observing a group of 120 college students in an online pharmacist program, Wellman and Marcinkiewicz (2004) found that time spent online by learners was only weakly correlated with learning.

This variability in the results of studies examining the relationship between quantitative time-on-task and performance in face-to-face and online learning activities might be explained by (1) the different methodologies used in assessing time-on-task and academic performance and their reliability (Schuman et al., 1985); (2) differences in the time quality of the time-on-task spent; and (3) the impact of compulsory, formal academic time spent by students working together during class-based courses in face-to-face contexts. In distance education, students have the ability to decide how to allocate their time according to instructional time flexibility. The amount of self-regulated time-on-task in face-to-face 
educational contexts is part of the time spent outside of the classroom; in distance education, self-regulated time comprises all the instructional time that is available for the student to regulate.

We therefore propose to analyze the relationship between time-on-task and performance, introducing the concept of quality cognitive time as a major attribute of the time-on-task spent. We propose to explain the differences in the relationship between quantitative timeon-task and performance in face-to-face and online learning activities by including the quality of time spent on academic activities in our analysis of the impact the quantity and quality of learners' time-on-task have on their academic performance.

\section{Learning Time Quality According to the Time of Day (oo:oo to 24:00)}

Time quality is made up of attributes related to a certain kind of activity. In academic settings, the quality of students' learning time is considered to be cognitive, an attribute that facilitates success in the learning process. Depending on the nature of the learning activities, different attributes of the students' time are required. These attributes depend not only on the task difficulty (Belmont \& Butterfield, 1971; Kobasigawa \& Metcalf-Haggert, 1993) but also on whether learning is individual or collaborative. In collaborative learning tasks, students need to regulate their own time-on-task-in terms of quantity, quality, and synchronicity-according to the learning times of their fellow students (Romero, 2010). Both in individual and collective learning activities, we consider the quality of learning time to be defined by the degree of sustained attention and lack of interruption, the degree of cognitive capability, and the emotional state of the student. Time of day is one of the indicators that has been used to define time quality. Some researchers have analyzed the degree of alertness by monitoring physiological indicators as they change during the day. The early work of Blake (1967) suggested that alertness changes depending on the time of day and introduced the term "post-lunch dip" to describe the diminished attention observed after lunch. In academic settings, Lewis and his colleagues (1988) observed that concentration levels were higher at 7 p.m. among undergraduates at Cambridge University. However, physiological indicators of actual alertness and alertness as perceived by the subjects might be different, according to Kramer and his colleagues (2000). In their study, subjects stated that their alertness was highest at 11 a.m. and 3 p.m., while physiological indicators pointed to higher alertness at 7 a.m. and 9 p.m. These studies were carried out among individuals engaged in a single, primary activity (professional or academic). In distance education, adult learners have primary professional, social, or family responsibilities, and distance studies are considered to be secondary. We might therefore expect students to engage in learning time after their primary activity, at a time of day when alertness is lower, both because of the time of day and the fatigue caused by the primary activity, assuming that, in general terms, the evening and night are times when cognitive quality is diminished and the morning and weekends are the times with the highest cognitive quality because of the absence of a previous activity. 


\section{Objectives}

Wishing to examine the impact of quantity and quality of academic time-on-task spent by students enrolled in online education programs, we conducted the analysis within a course that combined individual and collaborative activities. We looked at the students' time flexibility and had them record their working hours and time-on-task engagement for each major period of the day (morning, afternoon, evening, night) on both weekdays and weekends. We tested the relation between performance and time-on-task allocation during the morning and weekend because there was no previous activity and a higher degree of quality cognitive time available during those periods. We then compared these time attributes with the students' grades in both individual and collaborative activities in order to analyze which factors are relevant in each context.

Two main hypotheses were formulated for the purpose of these tests. The first hypothesis proposes an overall positive relation between the time-on-task devoted by students and their academic performance in individual and collaborative activities. The second hypothesis posits higher performance in individual and collaborative learning activities engaged in during the morning and weekend days.

\section{Context and Methodology}

The study was conducted with master's students $(N=48)$ enrolled in a compulsory course titled Learning Scenarios in Online Learning during the second semester of the 20092010 academic year at the UOC virtual campus. The course was composed of five activities, the first of which was individual and not graded. The second and third activities were also individual activities, followed by the last two activities, which were collaborative and carried out in groups of four. These groups were created homogeneously and took into account the individual grades obtained in the previous activities. All the activities were written assignments related to each of the topics covered in the course. Both in individual and collective assignments, students were able to regulate their time-on-task between the start of the task and the deadline for the assignment to be submitted. These written papers can be considered ill-defined tasks inasmuch as the task statements did not include all the information and organization required to carry them out (Chi \& Glaser, 1985). From the point of view of learning regulation, these tasks are not only regulated by students (self-regulated learning) in the case of the individual assignments but also by their peers (co-regulated) in the collaborative assignments. In ill-defined, self-regulated, and co-regulated learning activities, students must organize and regulate their own time-on-task engagement. In this case, low external regulation and task definition increases student responsibility for defining the task and regulating the learning process.

At the end of the course, the students recorded the hours they worked per week, their weekly engagement in learning tasks, and the time of day these were completed (morning, afternoon, evening, night), as well as the weekdays or weekend days spent during the course. We collected the students' records of the time-on-task with the EuroCAT tool (Lambropoulos, 
Faulkner, \& Culwin, 2011; Romero \& Demeure, 2010), which not only supported the definition of the students' weekly temporal engagement in their online education but also their professional activities. Student time flexibility was defined as the number of different times in a day the student could engage in the learning activity. More specifically, time flexibility was defined as the range of times during the weekdays or weekend days students were able to spend on the learning activities during the course according to their EuroCAT declaration. The maximum degree of time flexibility was attained by students who were able to work at any time of day on any day of the week. Those students with a high degree of time flexibility are, therefore, potentially able to regulate their time-on-task more easily because they can allocate the best quality time to carrying out their individual and collective learning activities.

\section{Results}

We analyzed the time attributes (flexibility, time of day, working time, time-on-task) and academic performance for four learning activities (two individual and two collective). First we will present the results that compare academic performance, time flexibility, working time, and time-on-task. Second, we will focus on the impact of the time of day on performance in individual and collective activities.

\section{Academic Performance, Time Flexibility, Working Time, and Time-on-Task}

For the first hypothesis (an overall positive relation between the time-on-task devoted by students and their academic performance), we observed a slight correlation between the time-on-task devoted by students on a weekly basis and their academic performance $(r=$ .31). A greater correlation was observed with the number of hours devoted to their professional activity $(r=.77)$ and especially the degree of time flexibility $(r=.98)$. Time flexibility was more significantly related to collaborative activity grades $(r=.91)$ than it was to individual activity grades $(r=.55)$.

\section{Time of Day and Academic Performance in Individual and Col- laborative Activities}

The relation between the time of day and academic performances was tested for the second hypothesis (higher performance in individual and collaborative learning activities engaged in during the morning and weekend days). There were no significant differences regarding the time of day and academic performance, except the morning period. Students who were able to work in the morning obtained the best overall grades $(r=.87)$. Considering only individual activity grades, we found that morning study was related to the best grades $(r$ $=.93$ ) but that evening availability was also closely related to academic performance $(r=$ .83). In collaborative activity, grades we observed for learning activities done in the morning were related only moderately to academic performance $(r=.46)$, while evening time availability was more significantly related $(r=.59)$. 


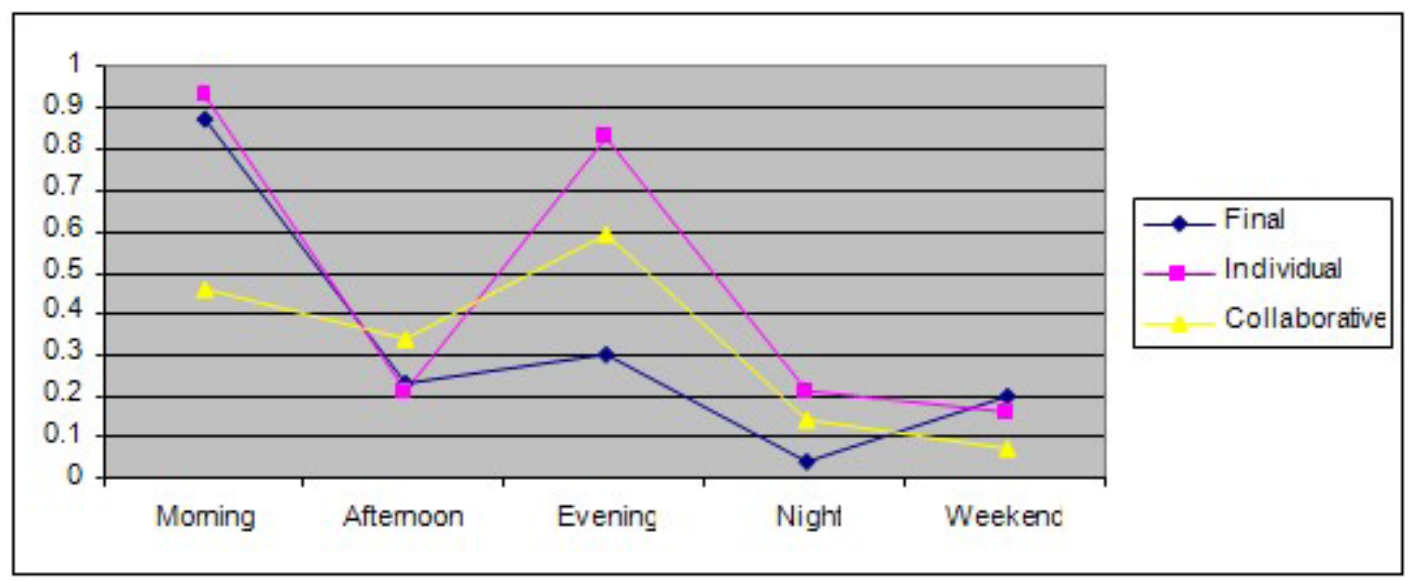

Figure 1. The impact of study at different times of the day on final grades, individual activity grades, and collaborative activity grades.

\section{Discussion and Conclusion}

Time flexibility in e-learning can be considered from either an instructional or studentcentred perspective. Time flexibility is reduced by increased course and activity structure, collaborative learning and, particularly, synchronic communication. Students' time flexibility, understood as the capacity to spend time-on-task at different times of the day and week, is reduced by their professional, social, and family commitments. In this study, we observed that students' time flexibility, defined as the number of different times a student could engage in the learning activity in a day, was the most relevant factor. Students who were able to work in the morning obtained the best overall grades $(r=.87)$, especially in individual activities. This finding could be viewed from the perspective of the quality of student time, which is better in the morning (Baddeley, Hatter, Scott, \& Snashall, 1970; Goldstein, Hahn, Hasher, Wiprzycka, \& Zelazo, 2007). However, we also observed a close relationship between the evening time slot and better academic performance in collaborative activities. For adult learners who work during the day, the time when most are available for learning activities is in the evening and on weekends (Kasprzak \& Nixon, 2004), but only a minority of the e-learners taking part in the course said that they were available on the weekend. The greatest shared availability is, therefore, in the evening. We analyzed this evening orientation from the point of view of synchronicity. Even when the task required no synchronicity per se, part of the collaborative work done by the students included synchronous discussions, mainly carried out via the instant messaging tools provided by the virtual campus. We observed that although the time slot most closely related to strong academic performance is the morning, which provides high-quality learning time, the availability of low-quality evening time is also closely related to strong performance in collaborative activities. 
Considering that the morning is the highest quality time and the most closely related to strong academic performance, educators should consider raising awareness about these findings among students and promote either their use of time available on the weekend or a change in professional and social activities to enable them to devote a greater part of their time in the morning to study. In the case of collaborative learning, we should help students to organize and regulate their exchanges asynchronously in order to avoid synchronous meetings in the evening, even if this is the most readily available time for the group. Ensuring quality time for e-learning might therefore reduce time flexibility and increase asynchronicity while raising student awareness about the need to use quality time both for their individual and collaborative activities. Increasing quality in e-learning also raises the quality of students' time devoted to learning activities in general. Finally, in future studies examining time-on-task in e-learning, we should consider not only the effects of online learners' quality time allocation in their performances but also the overall increase in online learning satisfaction. 


\section{References}

Allen, G. J., Lerner, W. M., \& Hinrichsen, J. J. (1972). Study behaviors and their relationships to test anxiety and academic performance. Psychological Reports, 30, 407410.

Arneberg P., Keegan D., Guardia, L., Keegan, D., Lõssenko, J., Fernández Michels, P., \& Zarka, D. (2007). Analyses of European megaproviders of e-learning. Bekkestua: NKIforlaget.

Baddeley, A., Hatter, I., Scott, D., \& Snashall, A. (1970). Memory and time of day. Quarterly Journal of Experimental Psychology, 22, 605-60.

Belmont, J. M., \& Butterfield, E. C. (1971). Learning strategies as determinants of memory deficiencies. Cognitive Psychology, 2(4), 411-420.

Blake, M. J. F. (1967). Relationship between circadian rhythm of body temperature and introversion-extroversion. Nature, 215, 896-897.

Boisot, M. (1998). Knowledge assets: Securing competitive advantage in the information economy. Oxford: Oxford University Press.

Chi, M. T. H., \& Glaser, R. (1985). Problem solving ability. In R. Sternberg (Ed.), Human abilities: An information-processing approach (pp. 227-257). San Francisco: W. H. Freeman \& Co.

Collis, B. (1998). New didactics for university instruction: Why and how? Computers and Education, 31(4), 373-393.

Collis, B., Vingerhoets, J., \& Moonen, J. (1997). Flexibility as a key construct in European training: Experiences from the TeleScopia project. British Journal of Educational Technology, 28(3), 199-217.

Cross, K. P. (1999, June). Learning is about making connections. The cross papers number 3. Princeton, NJ: League for Innovation in the Community College \& Educational Testing Service. Retrieved from ERIC (ED 432314).

De Boer, W., \& Collis, B. (2005). Becoming more systematic about flexible learning: Beyond time and distance. $A L T-J, 13(1), 33-48$.

Dev, P. C. (1997). Intrinsic motivation and academic achievement: What does their relationship imply for the classroom teacher? Remedial and Special Education, 18(1), 12-19.

Diaz, D. P. (2002, May/June). Online drop rates revisited. The Technology Source, 93-106. 
Douthitt, R. A. (2000). Time to do the chores? Factoring home production needs into measures of poverty. Journal of Family and Economic Issues, 21(1), 7-22.

Ehlers, U. (2004). Quality in e-learning from a learner's perspective. European Journal of Open Distance and E-Learning. Retrieved from http://www.eurodl.org/index.ph $\mathrm{p} ? \mathrm{p}=$ archives\&year $=2004$ \&halfyear $=1 \&$ article $=101$

Felix, U. (2001). A multivariate analysis of students' experience of web-based learning. Australian Journal of Educational Technology, 17(1), 21-36.

Goldstein, D., Hahn, C., Hasher, L., Wiprzycka, L. J., \& Zelazo, P. D. (2007). Time of day, intellectual performance, and behavioral problems in morning versus evening type adolescents: Is there a synchrony effect? Personality and Individual Differences, $43,431-440$.

Greenwald, A. G., \& Gilmore, G. M. (1997b). No pain, no gain? The importance of measuring course workload in student ratings of instruction. Journal of Educational Psychology, 89(4), 743-751.

Grundspenkis, J., Lavendels, J., Novickis, L., \& Shitikov, V. (2006, February). Compatibility of the principles of computer-based and classical teaching. Proceedings of the International Conference on Web-based communities, San Sebastian, Spain.

Harasim, L., (1990). Online education: An environment for collaboration and intellectual amplification. In L. Harasim (Ed.), Online education: Perspectives on a new environment (pp. 133-169). New York: Praeger.

Hinrichsen, J. J. (1972). Prediction of grade point average from estimated study behaviors. Psychological Reports, 31(3), 974-975.

Högskoleverket (2008). E-learning quality: Aspects and criteria for evaluation of e-learning in higher education. The Swedish National Agency for Higher Education. Högskoleverkets rapportserie 2008:11 R.

Kanuka, H. (2002). A principled approach to facilitating diverse strategies for web-based distance education. Journal of Distance Education, 17(2), 71-87.

Kasprzak, J., \& Nixon, M. (2004). Cheating in cyberspace: Maintaining quality in online education. American Association of Computing in Education Journal, 12(1), 85-99.

Kobasigawa, A., \& Metcalf-Haggert, A. (1993). Spontaneous allocation of study time by first- and third-grade children in a simple memory task. The Journal of Genetic Psychology, 154, 223-235.

Kolari, S., Savander-Ranne, C., \& Viskari, E-L. (2008) Learning needs time and effort: A time-use study of engineering students. European Journal of Engineering Educa- 
tion, 33(5-6), 483-498.

Kramer, A. F., Hahn, S., Irwin, D. E., \& Theeuwes, J. (2000). Age differences in the control of looking behavior: Do you know where your eyes have been? Psychological Science, $11,210-217$.

Lambropoulos, N., Faulkner, X., \& Culwin, F. (2011). Supporting social awareness in collaborative e-learning. British Journal of Educational Technology, 42. doi: 10.1111/j.1467-8535.2011.01184.x

Lavie, P. (1986). Ultrashort sleep-waking schedule: III. Gates and forbidden zones for sleep. Electroencephal. Clinocañ Neurophysiole, 63, 414-425.

Levinsen, K. (2006). Collaborative on-line teaching: The inevitable path to deep learning and knowledge sharing? Electronic Journal of E-learning, 4(1), 41-48.

Lewis, G., Robertson, I., Watson, P., \& Datta, A. (1998). Circadian rhythm of sleepiness and vigilance studied in man. Journal of Physiology, 506.

Lorenzetti, J. P. (2005, August 1). How e-learning is changing higher education: A new look. Distance Education Report, 4-7.

McGorry, S. Y. (2003). Measuring quality in online programs. The Internet \& Higher Education, $6,159-177$.

Moore, M. G., \& Kearsley, G. (1996). Distance education: A system view. Boston: Wadsworth Publishing Company.

Palloff, R., \& Pratt, K. (2003). The virtual student: A profile and guide to working with online learners. San Francisco, CA: Jossey-Bass.

Romero, M. (2010). Gestion du temps dans les Activités Projet Médiatisées à Distance (thèse de Doctorat en cotutelle européenne). Université de Toulouse (CLLE-LTC UMR CNRS 5263) et Universitat Autònoma de Barcelona (SINTE SGR 2009 134).

Romero, M., \& Lambropoulos, N. (2010, October). Group awareness in time-on-task regulation in CSCL. Paper presented at TACONET Worskshop. Self-regulated Learning in Technology Enhanced Learning Environments: Problems and Promises, Universitat de Barcelona.

Romero, M., \& Lambropoulos, N. (2011). Internal and external regulation to support knowledge construction and convergence in CSCL. Electronic Journal of Research in Educational Psychology, 9(1), 309-330.

Schellekens, A., Paas, F., \& Van Merriënboer, J. J. G. (2003). Flexibility in higher professional education: A survey in business administration programmes in the Netherlands. Higher Education, 45, 281-305. 
Schrum, L. (2002). Oh, what wonders you will see: Distance education past, present, and future. Learning and Leading with Technology, 30(3), 6-9.

Schuman, G.E., E.M. Taylor, Jr., F. Rauzi, \& B.A. Pinchak. 1985. Revegetation of mined land: Influence of topsoil depth and mulching method. Journal of Soil and Water Conservation, 40, 249-252.

Sullivan, P. (2001). Gender differences and the online classroom: Male and female college students evaluate their experiences. Community College Journal of Research \& Practice, $\quad$ 25(10), 805-818.

Trautwein, U. (2007). The homework-achievement relation reconsidered: Differentiating homework time, homework frequency, and homework effort. Learning and Instruction, 17(3), 372-388.

Valenta, A., Therriault, D., Dieter, M., \& Mrtek R. (2001). Identifying student attitudes and learning styles in distance education. Journal of Asynchronous Learning Networks, 5(2), 111-127.

Van den Brande, L. (1994). Flexible and distance learning. Chichester: John Wiley \& Sons.

Vergidis, D., \& Panagiotakopoulos, C. (2002). Student dropout at the Hellenic Open University: Evaluation of the graduate program studies in education. International Review of Research in Open and Distance Learning, 3(2).

Wagner, P., Schober, B., \& Spiel, C. (2008). Time students spend working at home for school. Learning and Instruction, 18, 309-320.

Wagstaff, R., \& Mahmoudi, H. (1976). Relation of study behaviors and employment to academic performance. Psychological Reports, 38, 380-382.

Wellman, G. S., \& Marcinkiewicz, H. (2004). Online learning and time-on-task: Impact of proctored vs. un-proctored testing. Journal for Asynchronous Learning Networks, 8(4), 93-104.

Wolk, S. (2001). The benefits of exploratory time. Educational Leadership, 59(2), 56-59.

Zhang, D., Zhao, J. L., Zhou, L., \& Nunamaker, J. F. Jr. (2004). Can e-learning replace classroom learning? Communications of the ACM, 47(5), 75-79.

\section{Athabasca University $\mathbf{1}$}

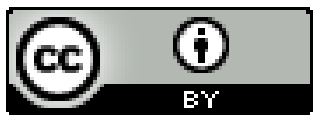

